\title{
Two Case Reports of Antrorhinoliths
}

\author{
${ }^{1}$ Santosh Kumar Swain, ${ }^{2}$ Ranjan Kumar Sahoo, ${ }^{3}$ Mahesh Chandra Sahu
}

\begin{abstract}
Antrorhinolith is an uncommon nasal mineralized mass of nasal cavity invading into maxillary sinus. Most antrorhinoliths are small and asymptomatic, caused by calcification of a nidus and are detected incidentally on radiological examination. Sometimes they present symptoms like pain and foul smelling nasal discharge. Here, we are presenting two cases of antrorhinoliths. One was found after endoscopic sinus surgery and second one was seen in patient with prolonged use of topiramate medication. In all these two cases, radiological examination revealed a discrete bony density in the nasal cavity and maxillary sinus which was blocking the ostiomeatal complex. The bony mass was removed endoscopically from the nasal cavity and maxillary sinus with drainage of discharge and debris from the sinuses. Histopathological examination revealed an antrolith with bony nidus and calcium deposited around it.
\end{abstract}

Keywords: Antrorhinolith, Endoscopic sinus surgery, Rhinolith

How to cite this article: Swain SK, Sahoo RK, Sahu MC. Two Case Reports of Antrorhinoliths. Int J Otorhinolaryngol Clin 2014;6(3):118-120.

Source of support: Nil

Conflict of interest: None

\section{INTRODUCTION}

Antrorhinolith is the lithiasis or stone formation in the nose and maxillary antrum. Antrorhinolith origins as rhinolith followed by invasion into maxillary sinus through its medial wall. Antrorhinolith is the presence of nasal mass which is composed of calcium carbonate, magnesium carbonate, calcium phosphate and magnesium phosphate. It develops around organic or inorganic nidus having irregular or spongy surface that has stayed in the nasal cavity for a long time. Nidus arises in most of the cases from an exogenous origin, such as fruit seeds, grains of vegetables and legumes, pieces of paper, button,

${ }^{1,2}$ Associate Professor, ${ }^{3}$ Research Associate

${ }^{1}$ Department of ENT, Institute of Medical Sciences and SUM Hospital, Bhubaneswar, Odisha, India

${ }^{2}$ Department of Radiology, Institute of Medical Sciences and SUM Hospital, Bhubaneswar, Odisha, India

${ }^{3}$ Department of Central Research Lab, Institute of Medical Sciences and SUM Hospital, Bhubaneswar, Odisha, India

Corresponding Author: Santosh Kumar Swain, Associate Professor, Department of ENT, Institute of Medical Sciences and SUM Hospital, Bhubaneswar, Odisha, India, Phone: 067423 86292, e-mail: swainsantoshbbsr@yahoo.com bead, pieces of toy and finally pieces of stone and sand. They rarely arise from an endogenous nidus. Endogenous nidus generally consists of mislocated tooth, pieces of bone, blood clot, dried purulent secretion or desquamated epithelium. The dimensions of antrorhinolith can be small or can fill the nasal cavity. Antrorhinolith cases are rare and patients frequently complain of longstanding nasal obstruction, nasal and oral malodor, purulent rhinorrhea and chronic headache. But sometimes patients with antrorhinoliths are coincidentally diagnosed during routine physical examination. Early diagnosis is essential to reduce the morbidity.

The first well documented case of rhinolithiasis was reported by Barthdinin in 1654. ${ }^{1}$ They may form around a nidus or a concentrated mucus where precipitation of calcium salts accumulate in concentric layer. ${ }^{2}$ Smaller antrorhinoliths are usually discovered incidentally on routine radiography. As the size of antrorhinolith increases, they will give rises to complications, like dacryocystitis, otorrhea, fetor, anosmia, palatal perforation and septal perforation. ${ }^{3}$ Early diagnosis and treatment helps to reduce morbidity of antrorhinoliths.

\section{CASE REPORTS}

\section{Case 1}

In the first case, 45 years aged one female presented in the ENT Outpatient Department (OPD) with complaint of nasal obstruction on the right side since 2 years. There was history of thick, foul smelling yellow nasal discharge from right nostril since 6 months. There was no history of any foreign body in the nose, hypertension, diabetes mellitus, tuberculosis or other relevant systemic illness in the past. She had undergone endoscopic sinus surgery 5 years back for sinusitis. The patient belonged to a rural background and had never gone for follow-up after surgery. On anterior rhinoscopy, an irregular, grey, stony mass covered with secretions was present in the right nostril, which on probing gave a gritty sensation. It was adherent to the middle meatus. A computed tomography (CT) scan of paranasal sinus was done which was showing a marked radiopaque mass in the right side of the nasal cavity invading into the right side maxillary sinus. On the basis of history, the clinical examination, diagnostic nasal endoscopy and CT scan (Fig. 1), the patient was diagnosed as antrorhinolith at the right side of the nasal cavity. 


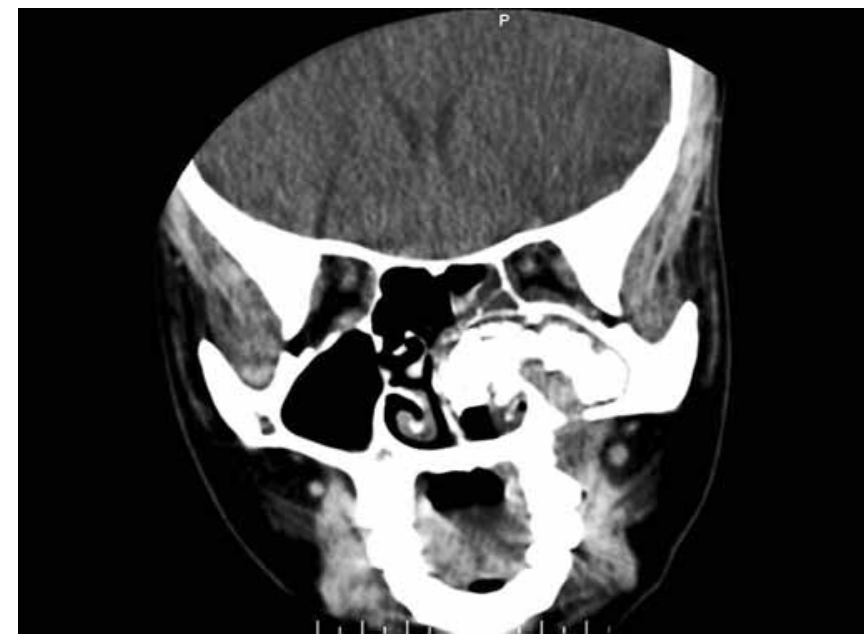

Fig. 1: Computed tomography scan showing antrorhinolith

\section{Case 2}

A 48-year-old man came to ENT OPD with nasal blockage and foul smelling discharge from nose. He had history of taking topiramate since 1 year for alcohol dependence. On anterior rhinoscopy and nasal endoscopy (Fig. 2) showed a grayish gritty foreign body in the nostril. Computed tomography scan of paranasal sinuses (Fig. 3) supports the diagnosis through the presence of calcified concretions in nasal cavity and invading into maxillary sinus. The patient was admitted for removal of the antrorhinoliths. Under general anesthesia, the nasal cavities were inspected by rigid nasal endoscope 0 degree. The antrorhinolith was gently mobilized, picked up and removed. Keeping in mind for nephrolithiasis as a complication by prolonged use of topiramate, an ultrasonography of abdomen done to rule out kidney stone. Kidney stone was confirmed in ultrasound. Then patient had weaned off topiramate and has begun another medication regimen for alcohol dependence.

\section{DISCUSSION}

Rhinoliths are rare, whereas antrorhinoliths are more rare. Rhinoliths vary in shape and size, from small to massive grow ths and may invade the adjacent structures like maxillary sinus. ${ }^{4}$ The rhinolith invading to maxillary sinus is called antrorhinolith. The formation of an antrorhinolith is thought to result from the longstanding presence of a foreign body or a nidus. A number of factors are thought to be involved in the formation of antrorhinolith. These include the entry and impaction of a foreign body in the nasal cavity, acute and chronic inflammation, obstruction and stagnation of the nasal secretions and precipitations of mineral salts. ${ }^{5}$ These nidi may be endogenous or exogenous. ${ }^{6}$ Our first case of antrorhinolith which was formed after endoscopic sinus surgery. In this case, blood clots or secretion or crusts may

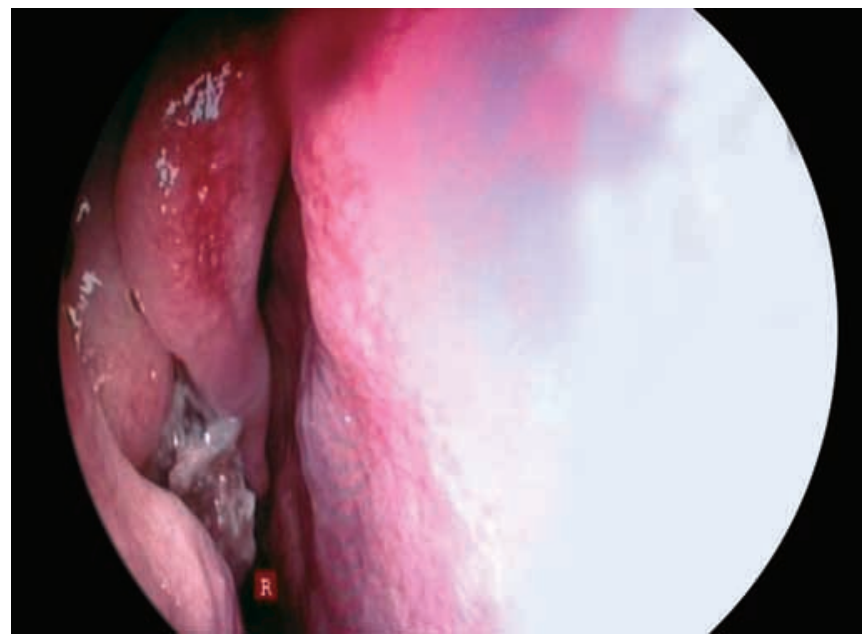

Fig. 2: Endoscopic photograph of antrorhinolith

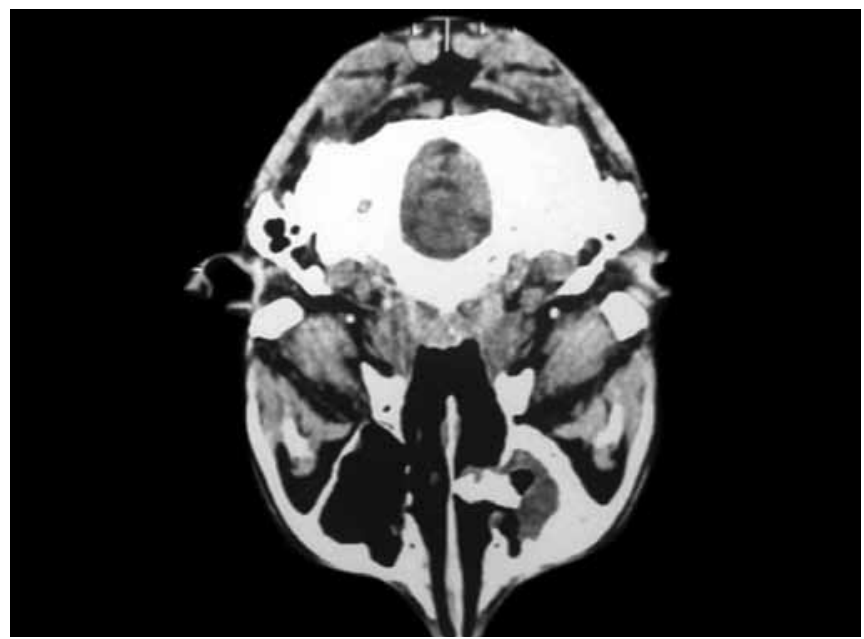

Fig. 3: Computed tomography scan showing stone in nose with extension into maxillary sinus

act as nidus for stone formation. In second case, there was no recognizable foreign body in the nose. Prolonged use of topiramate can cause metabolic acidosis which may be a cause of nephrolithiasis. ${ }^{7}$ It is difficult to explain the cause for antrorhinolith in this patient. Antrorhinolith may be rare coincidence or vomitus in nasal cavity due to alcohol addiction or metabolic acidosis in topiramate user create nidus formation for stone. According to literature, it is concluded that diagnostic nasal endoscopy is an ideal method for diagnosis of antrorhinolith. ${ }^{8}$ The size of the mass and its relations to adjacent structures in antrorhinolith can be assessed by CT scan. The differential diagnosis includes hemangioma, osteoma, calcified polyps, enchondroma, angiofibroma, ameloblastic fibro-odontoma, ameloblastic sarcoma, dermoid tumor, chondrosarcoma and osteosarcoma in the malignant tumor category; and syphilis and tuberculosis with calcifications in the inflammatory category. ${ }^{9,10}$ Treatment is total extraction of antrorhinolith. Stone can be removed by an endoscopic approach using either local or general 
anesthesia. If the antrorhinolith are unable to remove by endoscopic approach do Caldwell-Luc surgery. ${ }^{11}$ Two cases of our antrorhinoliths were removed intranasally by endoscope.

\section{CONCLUSION}

Although antrorhinolith's are very rare, clinicians should be aware of the possibility of their incidence after endoscopic sinus surgery. Patient needs regular nasal cleaning with endoscope or nasal douching with normal saline after endoscopic sinus surgery for preventing accumulation of secretions, crusts or blood clots which can act as nidus for rhinolith or antrorhinolith. It is difficult to explain the cause of antrorhinolith in patients with prolonged use of topiramate. It may be a rare coincidence or vomitus in nasal cavity due to alcohol addiction or metabolic acidosis in topiramate user creates nidus for stone formation. Though rarely observed, sinonasal concretions can be the source of foul smell from the nose and, therefore, a social concern for patient.

\section{ACKNOWLEDGMENT}

The authors are thankful to chairman and managing member of Siksha 'O' Anusandhan University, Bhubaneswar for their encouragement.

\section{REFERENCES}

1. Appelton SS, Kimbough RE, Engstrom HI. Rhinolithiasis: a review. Oral Surg Oral Med Pathol 1998;65(6):693-698.

2. Polson CJ. On rhinoliths. J Laryngol Otol 1943;58(3):79-116.

3. Sudhakar S, Kumar BP, Prabhat MPV. Rhinolith: a case report and review of literature. J Ind Academy Oral Med Radiol 2010;22(3):165-167.

4. Perrone JA. An unusual rhinolith. Laryngoscope 1968;78(2): 279-280.

5. Kuckowski J, Narozny W, Milkaszewski B, Stankiewicz C. Suppurative complications of frontal sinusitis in children. Clin Pediatric 2005;44(8):675-682.

6. Eliachar I, Schalit M. Rhinolithiasis: Report of eight cases. Arch Otolaryngol 1970;91(1):88-90.

7. Welch BJ, Graybeal D, Moe OW, Maalouf NM. Biochemical and stone risk profiles with topiramate treatment. Am J Kidney Dis 2006;48(4):555-563.

8. Stoney P, Bingham B, Okuda I, Hawke M. Diagnosis of rhinolith with rigid endoscopy. J Otolaryngol 1991;20(6): 408-411.

9. Sumbullu MA, Tozoglu U, Yoruk O, Yilmaz AB, Ucuncu H. Rhinolithiasis: the importance of flat panel detector based cone beam computed tomography in diagnosis and treatment. Oral Surg Oral Med Oral Pathol Oral Radiol Endod 2009;107(6): 65-67.

10. Ozdemir S, Akbas Y, Gorgulu O, Selcuk T, Sayar Rhinolithiasis: Review of 21 cases. Am J Rhinol Allergy 2010;24(6):136-139.

11. Ahire D. Chronic sinusitis leads to sinolith formation in maxillary sinus-a rare case. Open Access Scientific Reports 2013;2(3):670 